Published in final edited form as:

Cancer Epidemiol Biomarkers Prev. 2005 June ; 14(6): 1496-1501.

\title{
Energy Balance and Breast Cancer Risk
}

\author{
Alecia Malin ${ }^{1}$, Charles E. Matthews ${ }^{2}$, Xiao-Ou Shu ${ }^{2}$, Hui Cai ${ }^{2}, \mathrm{Qi} \mathrm{Dai}^{2}$, Fan Jin ${ }^{3}$, Yu-Tang \\ $\mathrm{Gao}^{3}$, and Wei Zheng ${ }^{2}$ \\ 1 Department of Surgery, Meharry Medical College; \\ 2 Division of General Internal Medicine, Department of Medicine, Vanderbilt-Ingram Cancer Center, \\ Vanderbilt University Medical School, Nashville, Tennessee; and
}

3 Shanghai Cancer Institute, Shanghai, People's Republic of China

\section{Abstract}

We evaluated the hypothesis that a pattern of behavioral exposures indicating positive energy balance [i.e., less exercise/sport activity, high body mass index (BMI), or high energy intake] would be associated with an increased breast cancer risk in the Shanghai Breast Cancer Study, a populationbased study of 1,459 incident breast cancer cases and 1,556 age frequency-matched controls.

Participants completed in-person interviews that collected information on breast cancer risk factors, usual dietary intake and physical activity in adulthood. Anthropometric indices were measured. Odds ratios and $95 \%$ confidence intervals were estimated by logistic regression to describe the individual and joint effects of the exposures on breast cancer risk. Lack of exercise/sport activity, low occupational activity, and high BMI were all individually associated with increased risk of breast cancer [odds ratios (OR) ranged from 1.49 to 1.86]. In general, women with lower exercise/sport activity level and higher BMI, or those with higher energy intake, were at an increased risk compared with women who reported more exercise/sport activities, had lower BMIs, or reported less energy intake. There was a significant multiplicative interaction $(P=0.02)$ between adult exercise/sport activity and BMI, with inactive women in the upper BMI quartile being at increased risk (OR, 2.16; 95\% confidence interval, 1.25-3.74) compared with their active and lean counterparts. This association was stronger in postmenopausal than in premenopausal women, and nonexercising postmenopausal women with higher BMIs were at substantially increased risk (OR, 4.74; 95\% confidence interval, 2.05-12.20). Our study suggests that promotion of behavior patterns that optimize energy balance (weight control and increasing physical activity) may be a viable option for breast cancer prevention.

\section{Introduction}

Restriction of calories by $10 \%$ to $40 \%$ of ad libitum intake inhibits mammary gland tumors in animal models by decreasing cell proliferation, increasing apoptosis, and possibly through antiangiogenic processes $(1,2)$. The effect of energy restriction on breast cancer risk has been examined in epidemiologic studies with mixed results. Michels et al. (3) prospectively followed a cohort of Swedish women diagnosed and treated for anorexia before age 40 and reported they had nearly half the risk of breast cancer compared with age-matched controls. Studies examining the influence of war-related famine on breast cancer have provided conflicting results with one study suggesting decreased risk (4), and another study suggesting increased risk (5), for women exposed to short-lived famine conditions. In contrast, premenopausal

Requests for reprints: Alecia Malin, Department of Surgery, Meharry Medical College, 1005 Dr. D.B. Todd Boulevard, Nashville, TN 37208. Phone: 615-327-5719; Fax: 615-327-5579. E-mail: amalin@ mmc.edu.

Grant support: U.S. Public Health Service grant R01-CA64277 from the National Cancer Institute and a postdoctoral training award DAMD17-01-0437 from the U.S. Army Medical Research and Materiel Command (A. Malin). 
obesity is associated with reduced risk of the disease, whereas postmenopausal obesity is associated with increased risk (6). Long-term participation in high levels of physical activity has also been associated with reduced risk of the disease $(7,8)$. The independent effect of energy intake on breast cancer risk has been difficult to estimate because body size and physical activity are strong determinants of total energy expenditure (9).

Given the substantial level of weight gain in industrialized countries in the last two decades $(10,11)$, there is great interest in understanding the influence of energy balance on cancer risk and to develop preventive strategies that can effectively minimize excess risk. The potent anticancer effect of caloric restriction in animals is clear, but caloric restriction alone is not generally considered to be a feasible strategy for cancer prevention in humans. However, the identification and development of preventive strategies that "mimic" the anticancer effects of low energy intake are desirable (12). Caloric restriction limits systemic energy availability by restricting energy intake at a low level (1). Energy balance can be conceptualized as the difference between intake and expenditure and, thus, can be modulated by changes in intake, expenditure, or both $(1,13)$. Acute restriction of available energy in women, by dietary restriction, physical activity energy expenditure, or combinations of both, has been shown to produce a hormonal and metabolic milieu that mimics several features of caloric restriction and is consistent with a low risk for breast cancer (e.g., reduced insulin, less bioavailable insulin-like growth factor-I; refs. 12,14-17).

A methodologic problem in measuring energy balance, in particular energy intake, is the phenomena of subjects reporting lower energy intake than physiologically required, noted as underreporting (18). Underreporting of energy intake is expressed as a ratio of reported energy intake to estimated basal metabolic rate (EI/BMR ${ }_{\text {est }}$; refs. 19,20).

Serious underreporting of energy intake has mostly been observed in obese people (21-23). A higher body mass index (BMI) has been shown to be an independent predictor of low EI/ $\mathrm{BMR}_{\text {est }}(22,24,25)$. Underreporting energy intake in the obese population may be perpetuated by desire for weight change and level of dietary consciousness. Several studies suggest that obese underreporters are more likely to estimate low intakes of foods perceived unhealthy than those perceived as healthy $(25,26)$. Systematic underreporting differentiates across members of the study sample and may lead to bias in associations between food intake patterns and certain disease outcomes; in this case, associations between dietary intakes and obesity-related diseases like breast cancer.

There is limited research on underreporting and increased body size in the Asian population, primarily due to the low prevalence of obesity in the Asian population. Study results have been contradictory to the findings in other world populations where obese individuals are more likely to under-report. A recent study in Japanese female college students where $95 \%$ were classified as nonobese (BMI $<25 \mathrm{~kg} / \mathrm{m}^{2}$ ) revealed BMI, body weight, and basal metabolic rate decreased significantly with the increase in $\mathrm{EI} / \mathrm{BMR}_{\mathrm{est}}(P<0.001$; ref. 27$)$. In short, underreporting of energy intake was predominant in this relatively lean population.

Obesity also has a low prevalence in the Shanghai female population (28). To prevent underreporting, which is indicative in members of the female nonobese Asian population, the instrument used to assess energy intake was an interview administered in-person using a quantitative food frequency questionnaire, based on data from a 24-hour dietary survey in a validation study conducted in 200 Shanghai women (29) versus a self-administered, selfreported food frequency questionnaire. Self-reported dietary questionnaires have been proven to be prone to underestimated energy intake $(21,30)$.

We have previously reported significant associations of body size (weight, height) and weight gain (28), and high levels of exercise/sport activity (31) with breast cancer risk in the Shanghai 
Breast Cancer Study. In this report, we reevaluate indicators of energy balance that we have found previously to be associated with risk, as well as energy intake, and test the hypothesis that behavioral patterns indicating greater energy availability (i.e., low exercise/sport activity, high BMI, or high energy intake) may be associated with increased breast cancer risk compared with patterns of exposure indicating restricted energy availability (i.e., high exercise/sport activity and low BMI or low energy intake).

\section{Materials and Methods}

The Shanghai Breast Cancer Study was designed to recruit women ages 25 to 64 who were newly diagnosed with breast cancer, and a random sample of healthy controls. Study participants were permanent residents of urban Shanghai and were enrolled in the study between August 1996 and March 1998. Women with a prior history of cancer or who were deceased at the time of interview were not eligible for the study. Through a rapid case ascertainment system, supplemented by the population-based Shanghai Cancer Registry, 1,602 eligible incident breast cancer cases were identified during the study period and in-person interviews were completed for 1,459 (91.1\%) of them. Controls were randomly selected from female residents in urban Shanghai, using the population-based Shanghai Resident Registry, and frequency-matched to cases by age (5-year intervals). In-person interviews were completed with $1,556(90.3 \%)$ of 1,724 eligible controls.

Trained interviewers conducted an in-person interview and measured eligible women for weight, circumference of waist and hips, and height (according to a standard protocol; ref. 28). From these data, waist $/$ hip ratio and BMI $\left(\mathrm{kg} / \mathrm{m}^{2}\right)$ were calculated. The structured questionnaire elicited detailed information on demographic factors, menstrual and reproductive history, hormone use, dietary habits, prior disease history, physical activity, tobacco and alcohol use, and family history of cancer.

Usual adult dietary intake was collected using a comprehensive quantitative food frequency questionnaire that covers $>85 \%$ of commonly consumed foods in urban Shanghai (32). A physical activity questionnaire assessed exercise/sport activity and occupational activity levels. Women could report up to five exercises or sport activities during adolescence (13-19 years) and adulthood (last 10 years). Quantitative exercise/sport data were summarized in terms of intensity [metabolic equivalents (MET), duration (h/wk), years of participation, and average energy expenditure during the period (MET-h/wk/y) using standard methods; ref. 31]. Women also reported their occupational physical activity levels for jobs they held for at least 3 years during their lifetime. For each occupation, participants reported the average time spent in "standing or walking" and classified the physical exertion of the job according to three activity categories (i.e., heavy, medium, or nonphysical work). Summary measures were calculated by multiplying the years spent in each occupation by the specific activity variable and then summing the results over all jobs. A similar version of this physical activity questionnaire has been found to be a reliable and valid assessment of exercise and sports in Shanghai women (32).

$P$ values were derived from $t$ tests for univariate comparisons (Table 1). Unconditional logistic regression was used to derive adjusted odds ratios (OR) and 95\% confidence intervals (95\% $\mathrm{CI}$ ) to estimate the associations between breast cancer risk and the individual indicators of energy balance (exercise/sport activity, occupational activity, BMI, energy intake) as well as the joint effects of these exposures. Multivariate analyses were adjusted for the following variables: breast cancer in first-degree relative, history of breast fibroadenoma, household income, education, age at first live birth, height, and menopausal status when appropriate. Exposure levels for continuous variables, BMI, and energy intake were categorized according to quartile distributions among controls. Trend tests were conducted by treating categorical 
variables as the ordinal values of the quartile levels in the model. Multiplicative interactions were evaluated using the cross-product terms of relevant exposures along with the main effect terms in the model.

\section{Results}

The descriptive characteristics for cases and controls in the Shanghai Breast Cancer Study are presented in Table 1. Cases had an earlier age of menarche, later age of menopause, and first live birth. Proportionally more cases had breast fibroadenomas and first-degree relatives with breast cancer. There were positive associations between breast cancer risk and low levels of exercise/sport activity in adulthood and lifetime occupational activity, and increased BMI, waist/hip ratio, and adult height (Table 2). Greater energy intake alone was not associated with risk of breast cancer (Table 2).

The joint associations of these energy balance indicators reflecting gradations in energy availability with breast cancer are presented for all women and by menopausal status in Table 3. In general, women with combined patterns of exposure indicating a positive energy balance were at increased risk compare to women with exposure patterns indicating more restricted energy balance. That is, women with lower physical activity levels and higher BMIs, and low physical activity levels and high energy intakes, were at increased risk relative to women with higher activity levels who were lean and/or who reported consuming fewer calories (Table 3). A significant multiplicative interaction was found between exercise/sports activity and BMI (Table 3). Women reporting no exercise with BMIs $>25 \mathrm{~kg} / \mathrm{m}^{2}$ were at $>2$-fold increased risk compared with women reporting $>2.92$ MET-h/d/y of exercise with a BMI of $<21 \mathrm{~kg} / \mathrm{m}^{2}$.

Higher BMI was unrelated to breast cancer risk among women who exercised (OR, 0.75; $95 \%$ CI, 0.38-1.47). Similarly, lack of exercise was unrelated to risk among lean women (OR, 1.29; 95\% CI, 0.74-2.23).

The results revealed that the type of physical inactivity pattern differed markedly between premenopausal and postmenopausal women. Among premenopausal women, lack of exercise/ sport activity is not associated with risk (OR, 1.11; 95\% CI, 0.52-2.38), whereas low levels of occupational activity were associated with increased risk (OR, 2.21; 95\% CI, 1.20-4.20).

In contrast, low levels of both exercise/sport activity (OR, 4.74; 95\% CI, 2.00-11.19) and occupational activity (OR, 3.13; 95\% CI, 1.43-6.86) were associated with increased risk in postmenopausal women. This divergence between menopausal statuses may be explained by younger women engaging in more occupational physical activity and postmenopausal women (22\%) engaging in more exercise participation than their younger counterparts (13\%).

There was no indication of a joint effect between physical activity and energy intake on breast cancer risk among premenopausal women. This finding may reflect the much greater degree of measurement error using an in-person interview to measure food frequency intake than using measured weight and height used to calculate BMI. Joint presence of high-energy intake and low physical activity, however, was associated with a higher risk of breast cancer than each of these factors alone among postmenopausal women. However, test for multiplicative interaction were not statistically significant (Table 3).

Additional analyses were conducted to evaluate the three-way interactions between physical activity, energy intake, and BMI (Table 4). Highest risk was consistently observed for women who were less active, who were heavier, and who consumed more calories. High energy intake added minimal additional risk (Table 4). 


\section{Discussion}

Few epidemiologic studies of breast cancer have examined the joint effects of physical activity, body size, and energy intake on risk. Those studies that examine the effects of physical activity and body size provide inconclusive evidence on breast cancer risk. Some studies have suggested that higher levels of activity conferred the most benefit among lean postmenopausal (33) versus lean premenopausal women (34). On the other hand, some studies found that higher levels of physical activity are unrelated to postmenopausal (35) and premenopausal women's breast cancer risk $(36,37)$. In contrast, we found that increased breast cancer risk was associated with occupational inactivity in the higher BMI premenopausal population and with exercise/ sport inactivity in the higher BMI postmenopausal population.

Several explanations might explain a difference in the strength of association between physical activity, body size, and risk of breast cancer depending on menopausal status in our study.

Discrepancies in findings between studies may be attributed to lack of information about total or specific components of physical activity (thus, no information on occupational activity) in contrast to our study including both exercise/sport and occupational activity. This may explain why there are null findings on physical activity and premenopausal breast cancer risk $(36,37)$ and limited evidence that a lack of occupational activity is detrimental in the postmenopausal population $(33,35)$. Our study computed the intensity [metabolic equivalents (MET), duration (h/wk), years of participation, and average energy expenditure during the period (MET-h/wk/ y)] using standard methods allowing study of dose-response relationships and long-term effects of physical activity on breast cancer risk. This is in contrast to the Norwegian study that measured the total physical activity (recreational and occupational) using self-administered questionnaires (34) but did not measure the duration and intensity of the activities done.

The joint relationship between higher energy intake and breast cancer risk is less striking in this population. We have taken precautions to minimize underreporting and misclassification bias of energy intake by using a validated in-person food frequency questionnaire versus 24hour food records that may attenuate the associations between diet and disease. However, individual dietary habits are influenced by a host of social, cultural, customary, and economic factors; thus, assessments of diet in a relatively homogenous population may weaken the disease-diet relationship (38).

There is good evidence that restricted energy availability is associated with a hormonal and/ or metabolic milieu that would be predicted to reduce breast cancer risk $(16,39)$. For example, Loucks et al. (16) report that restricted energy availability was associated with reduced insulin and bioavailable insulin-like growth factor-I (e.g., insulin-like growth factor-I/insulin-like growth factor binding protein-3 ratio), as well as reduced leptin levels. C peptide and some elements of the insulin-like growth factor axis have been associated with breast cancer risk in the Shanghai Breast Cancer Study $(40,41)$ as well as a number of other breast cancer studies (42). Leptin levels have been positively associated with cell proliferation in mammary tissue and, thus, may be a growth factor that influences carcinogenesis $(43,44)$. Moreover, lower levels of energy availability have been associated with luteal phase deficiency (i.e., shorter luteal phase, lower progesterone) in premenopausal women (39). Among postmenopausal women, this exposure pattern would limit the accumulation of adipose tissue during adulthood and subsequently reduce postmenopausal estrogen exposure through aromatization of adrenal androgens (45).

Studies in animal models examining the combined effects of exercise and caloric restriction on cancer outcomes have provided mixed results. Holloszy (46) reported that both exercise and caloric restriction, and the combination of both, reduced cancer mortality. Kritchevsky (47) reported that these same exposures reduced tumor incidence and multiplicity for 
dimethylhydrazine-induced colon tumors in rats. In contrast, Gillette (48) failed to find evidence of an energy availability effect on 1-methyl-1-nitorsomethylurea-induced mammary tumors in rats. Clearly, more research is needed to elucidate the impact of patterns of behavior that favor lower levels of energy availability on cancer biomarkers and frank cancer outcomes.

Although we believe that these data are consistent with the energy availability hypothesis, we acknowledge some apparent inconsistencies in our results. The type of physical activity that conferred benefit was not consistent for premenopausal and postmenopausal women. Among premenopausal women, low levels of occupational activity were associated with increased risk, whereas among postmenopausal women low levels of both exercise/sport activity and occupational activity were associated with increased risk. This inconsistency may be explained by the lower prevalence of exercise/sport participation among premenopausal compared with postmenopausal women in these data, and because occupational physical activity contributes a greater proportion of overall physical activity energy expenditure in younger women. The discrepancies may also affect the opposite effect of BMI for premenopausal and postmenopausal breast cancer with energy intake. Interestingly, in this study, we also found that the joint effect of physical activity and energy intake was more evident among postmenopausal women, suggesting that energy balance may have differential effects on premenopausal and postmenopausal women.

This study has several strengths. It was a population-based, case-control study that included incident cases and that obtained detailed information about traditional breast cancer risk factors that allowed for full adjustment for possible confounding factors. Participation rates were high $(>90 \%)$ for both cases and controls, suggesting that the potential for selection bias in this study is low. The primary instruments used to obtain physical activity and dietary information in this study have been tested for reliability and validity in a population of women from Shanghai, and both were found to be reliable and valid instruments for stratifying women by physical activity and energy intake levels $(32,49)$. Another strength, distinct from other epidemiologic studies, is that BMI was calculated from measured rather than self-reported weight and height within days of cancer diagnosis, thus reducing measurement errors and some of the effects of therapy on body weight. In summary, we observed that women with higher levels of energy availability, by virtue of their low physical activity and high BMI or energy intake levels, were at an increased breast cancer risk compared with women with more restricted energy availability. These findings support current breast cancer prevention efforts that seek to increase physical activity levels and minimize age-related weight gain $(50,51)$. The relationship between these patterns of exposure modifying breast cancer risk and underlying biological mechanisms remains indeterminate, yet our findings are consistent with evidence that restricted energy availability can induce hormonal and metabolic changes that are consistent with reduced breast cancer risk. The fact that many of these pathways overlap with mechanisms proposed to explain the anticancer effect of caloric restriction suggests that balancing energy expenditure with intake may mimic some of the elements of caloric restriction.

Additional research is needed to document similar relationships in other study populations and to better understand the mechanisms underlying associations observed in this report. Further health promotion programs should be created to reduce the prevalence of overweight and sedentary lifestyle, two modifiable risk factors for breast cancer risk, and many other health risks for women.

\section{References}

1. Thompson HJ, Zhu Z, Jiang W. Dietary energy restriction in breast cancer prevention. J Mammary Gland Biol Neoplasia 2003;8:133 - 42. [PubMed: 14587868] 
2. Thompson HJ, Zhu Z, Jiang W. Identification of the apoptosis activation cascade induced in mammary carcinomas by energy restriction. Cancer Res 2004;64:1541 - 5. [PubMed: 14973070]

3. Michels KB, Ekbom A. Caloric restriction and incidence of breast cancer. JAMA 2004;291:1226 30. [PubMed: 15010444]

4. Elias SG, Peeters PH, Grobbee DE, et al. Breast cancer risk after caloric restriction during the 19441945 Dutch famine. J Natl Cancer Inst 2004;96:539 - 46. [PubMed: 15069116]

5. Tretli S, Gaard M. Lifestyle changes during adolescence and risk of breast cancer: an ecologic study of the effect of World War II in Norway. Cancer Causes Control 1996;7:507 - 12. [PubMed: 8877047]

6. IARC. Weight control and physical activity. Lyon (France): IARC; 2002.

7. Friedenreich CM. Physical activity and cancer prevention: from observational to intervention research. Cancer Epidemiol Biomarkers Prev 2001;10:287 - 301. [PubMed: 11319168]

8. Thune I, Furberg AS. Physical activity and cancer risk: dose-response and cancer, all sites and sitespecific. Med Sci Sports Exerc 2001;33:530 - 50.

9. Ravussin E, Lillioja S, Anderson TE, et al. Determinants of 24-hour energy expenditure in man. Methods and results using a respiratory chamber. J Clin Invest 1986;78:1568 - 78. [PubMed: 3782471]

10. Paeratakul S, Popkin BM, Keyou G, et al. Changes in diet and physical activity affect the body mass index of Chinese adults. Int J Obes Relat Metab Disord 1998;22:424 - 31. [PubMed: 9622339]

11. Mokdad AH, Serdula MK, Dietz WH, et al. The continuing epidemics of obesity and diabetes in the United States. JAMA 2001;286:1195 - 200. [PubMed: 11559264]

12. Hursting SD, Lavigne JA, Berrigan D, et al. Calorie restriction, aging, and cancer prevention: mechanisms of action and applicability to humans. Annu Rev Med 2003;54:131 - 52. [PubMed: 12525670]

13. Wade GN, Schneider JE, et al. Control of fertility by metabolic cues. Am J Physiol 1996;270:E1 19. [PubMed: 8772468]

14. Pike MC, Spicer DV, Dahmoush L, et al. Estrogens, progestogens, normal breast cell proliferation, and breast cancer risk. Epidemiol Rev 1993;15:17 - 35. [PubMed: 8405201]

15. Yu H, Rohan T. Role of the insulin-like growth factor family in cancer development and progression. J Natl Cancer Inst 2000;92:1472 - 89. [PubMed: 10995803]

16. Loucks AB. Energy availability, not body fatness, regulates reproductive function in women. Exerc Sport Sci Rev 2003;31:144 - 8. [PubMed: 12882481]

17. Loucks AB, Thuma JR. Luteinizing hormone pulsatility is disrupted at a threshold of energy availability in regularly menstruating women. J Clin Endocrinol Metab 2003;88:297 - 311. [PubMed: 12519869]

18. Voss S, Kroke A, Klipstein-Grobusch K, et al. Obesity as a major determinant of underreporting in self administered food frequency questionnaire: results from the EPIC-Potsdam Study. Z Ernahrungswiss 1997 Sep;36:229-36. [PubMed: 9399425]

19. Goldberg GR, Black A, Jebb SA, et al. Critical evaluation of energy intake data using fundamental principles of energy physiology: 1. derivation of cut-off limits to identify under-recording. Eur J Clin Nutr 1991;45:569 - 81. [PubMed: 1810719]

20. Haraldsdóttir J, Sandström B. Detection of underestimated energy intake in young adults. Int J Epidemiol 1994;23:577 - 82. [PubMed: 7960385]

21. Voss S, Kroke A, Klipstein-Grobusch K. Is macronutrient composition of dietary intake data affected by underreporting? Results from the EPIC-Potsdam Study. European Prospective Investigation into Cancer and Nutrition. Eur J Clin Nutr 1998 Feb;52:119-26. [PubMed: 9505157]

22. Johansson KS, Bjørneboe Gunn-Elin Aa, Drevon CA. Under- and over-reporting of energy intake related to weight status and lifestyle in a nationwide sample. Am J Clin Nutr 1998;68:266 - 74. [PubMed: 9701182]

23. Lavienja AJ, Braam LM, Ockè, Buenode-Mesquita HB, et al. Determinants of obesity-related underreporting of energy intake. Am J Epidemiol 1998;147:1081 - 6. [PubMed: 9620052]

24. McGowan MJ, Harrington KE, Kiely M, et al. An evaluation of energy intakes and the ratio of energy intake to estimated basal metabolic rate $\left(\mathrm{EI} / \mathrm{BMR}_{\mathrm{est}}\right)$ in the North/South Ireland food consumption survey. Public Health Nutr 2001;4:1043 - 50. [PubMed: 11820917] 
25. Mendez MA, Wynter S, Wilks R, et al. Under- and overreporting of energy is related to obesity, lifestyle factors and food group intakes in Jamaican adults. Public Health Nutr 2004;7:9 - 10. [PubMed: 14972067]

26. Scagliusi FB, Polacow VO, Guilherme G, et al. Selective underreporting of energy intake in women: magnitude, determinants, and effect of training. J Am Diet Assoc 2003;103:1306 - 13. [PubMed: 14520248]

27. Okubo H, Sasaki S. Underreporting of energy intake among Japanese women aged 18-20 years and its association with reported nutrient and food group intakes. Public Health Nutr 2004;7:911 - 7. [PubMed: 15482617]

28. Shu X-O, Jin F, Dai Q, et al. Association of body size and fat distribution with risk of breast cancer among Chinese women. Int J Cancer 2001;94:449 - 5. [PubMed: 11745429]

29. Malin AS, Qi D, Shu X-O, et al. Intake of fruits, vegetables and selected micronutrients in relation to the risk of breast cancer. Int J Cancer 2003;105:413 - 8. [PubMed: 12704679]

30. Black AE, Goldberg GR, Jebb SA, et al. Critical evaluation of energy intake data using fundamental principles of energy physiology 2. Evaluating the results of published surveys. Eur J Clin Nutr 1991;45:583 - 99. [PubMed: 1810720]

31. Matthews CE, Shu XO, Jin F, et al. Lifetime physical activity and breast cancer risk in the Shanghai Breast Cancer Study. Br J Cancer 2001;84:994 - 1001. [PubMed: 11286483]

32. Shu X-O, Yang G, Jin F, et al. Validity and reproducibility of the food frequency questionnaire used in the Shanghai Women's Health Study. Eur J Clin Nutr 2004;58:17 - 23. [PubMed: 14679362]

33. McTiernan A, Kooperberg C, White E, et al. Women's health initiative cohort study. recreational physical activity and the risk of breast cancer in postmenopausal women: the women's health initiative cohort study. JAMA 2003;290:1331 - 6. [PubMed: 12966124]

34. Thune I, Brenn T, Lund E, et al. Physical activity and the risk of breast cancer. N Engl J Med 1997;336:1269 - 75. [PubMed: 9113929]

35. Lee I-M, Rexrode KM, Cook NR, et al. Physical activity and breast cancer risk: the Women's Health Study (United States). Cancer Cause Control 2001;12:137 - 45.

36. Colditz GA, Feskanich D, Chen WY, et al. Physical activity and risk of breast cancer in premenopausal women. Br J Cancer 2003;89:847 - 51. [PubMed: 12942116]

37. Margolis KL, Mucci L, Braaten T, et al. Physical activity in different periods of life and the risk of breast cancer: the Norwegian-Swedish Women's Lifestyle and Health cohort study. Cancer Epidemiol Biomarkers Prev 2005;14:27 - 32. [PubMed: 15668472]

38. Hu G, Pekkarinen H, Hännien O, et al. Comparison of dietary and non-dietary risk factors in overweight and normal-weight Chinese adults. Br J Nutr 2002;88:91 - 7. [PubMed: 12117432]

39. De Souza MJ, Van Heest J, Demers LM, et al. Luteal phase deficiency in recreational runners: evidence for a hypometabolic state. J Clin Endocrinol Metab 2003;88:337 - 46. [PubMed: 12519874]

40. Yang G, Lu G, Jin F, et al. Population-based, case-control study of blood C-peptide level and breast cancer risk. Cancer Epidemiol Biomarkers Prev 2001;10:1207 - 11. [PubMed: 11700270]

41. Yu H, Jin F, Shu X-O, et al. Insulin-like growth factors and breast cancer risk in Chinese women. Cancer Epidemiol Biomarkers Prev 2002;11:705 - 12. [PubMed: 12163322]

42. Kaaks R, Lukanova A. Energy balance and cancer: the role of insulin and insulin-like growth factorI. Proc Nutr Soc 2001;60:91 - 106. [PubMed: 11310428]

43. Dieudonne MN, Machinal-Quelin F, Serazin-Leroy V. Leptin mediates a proliferative response in human MCF7 breast cancer cells. Biochem Biophys Res Commun 2002;293:622 - 8. [PubMed: 12054648]

44. Hu X, Juneja SC, Maihle NJ, et al. Leptin-A growth factor in normal and malignant breast cells and for normal mammary gland development. J Natl Cancer Inst 2002;94:1704 - 11. [PubMed: 12441326]

45. Key TJ, Allen NE, Verkasalo PK, et al. Energy balance and cancer: the role of sex hormones. Proc Nutr Soc 2001;60:81 - 9. [PubMed: 11310427]

46. Holloszy JO. Mortality rate and longevity of food-restricted exercising male rats: a reevaluation. J Appl Physiol 1997;82:399 - 403. [PubMed: 9049716] 
47. Kritchevsky D. Influence of caloric restriction and exercise on tumorigenesis in rats. Proc Soc Exp Biol Med 1990;193:35 - 8. [PubMed: 2104673]

48. Gillette CA, Zhu Z, Westerlind KC, et al. Energy availability and mammary carcinogenesis: effects of calorie restriction and exercise. Carcinogenesis 1997;18:1183 - 8. [PubMed: 9214601]

49. Matthews CE, Shu X-O, Yang G, et al. Reproducibility and validity of the Shanghai Women's Health Study physical activity questionnaire. Am J Epidemiol 2003;158:1114 - 22. [PubMed: 14630608]

50. Riboli, E.; Lambert, R.; Kleihues, P. Nutrition and cancer: a complex relationship. In: Riboli, E.;

Lambert, R., editors. In Nutrition and lifestyle: opportunities for cancer prevention. Lyon (France): IARC; 2002. p. 3-4.IARC scientific publications no. 156.

51. Jakicic JM, Clark K, Coleman E, et al. Appropriate intervention strategies for weight loss and prevention of weight regain for adults. Med Sci Sports Exerc 2001;33:2145 - 56. [PubMed: 11740312] 
Table 1

Comparisons of cases and controls on demographics and selected breast cancer risk factors (Shanghai Breast Cancer Study, 1996-1999)

\begin{tabular}{lcc}
\hline Characteristics & Cases $(\boldsymbol{n = 1 , 4 5 9 )}$ & Controls $(\boldsymbol{n}=\mathbf{1 , 5 5 6})$ \\
\hline Age & $47.93 \pm 7.99$ & $47.25 \pm 8.79$ \\
Education(\%) & 3.63 & 0.24 \\
$\quad$ No formal education & 8.50 & 5.46 \\
$\quad$ Elementary school & 74.3 & 8.42 \\
$\quad$ Middle + high school & 13.6 & 75.4 \\
$\quad$ Profession, college and above & 3.7 & 10.7 \\
Breast cancer in first-degree relatives $(\%)$ & 9.6 & 2.4 \\
Ever had breast fibroadenoma (\%) & 5.1 & 5.0 \\
Nulliparous (\%) & $26.7 \pm 4.2$ & 3.9 \\
Age at first live birth (y) & $14.5 \pm 1.6$ & 0.012 \\
Menarcheal age (y) & 34.5 & $26.2 \pm 3.9$ \\
Postmenopausal (\%) & $48.1 \pm 4.6$ & $14.7 \pm 1.7$ \\
Menopausal age (y) & & 36.2 \\
& & $<.126$ \\
\end{tabular}

* Among postmenopausal women only. 
Table 2

ORs and 95\% CIs for breast cancer risk associated with exercise/sport activity, occupational activity, BMI, waist/ hip ratio, height and energy intake

\begin{tabular}{|c|c|c|}
\hline & Case/control & OR $(95 \% \mathrm{CI})$ \\
\hline \multicolumn{3}{|c|}{ Adult exercise/sports (MET-h/d/y) } \\
\hline$>2.92$ & $11 / 18$ & 1.0 \\
\hline $0<\mathrm{h} \leq 2.92$ & $147 / 188$ & $1.33(0.96-1.83)$ \\
\hline 0 & $1,199 / 1,181$ & $1.86(1.44-2.41)$ \\
\hline$P_{\text {trend }}$ & $<0.001$ & \\
\hline \multicolumn{3}{|c|}{ Occupational activity (hours of standing work per day, $h / d / y$ ) } \\
\hline \multicolumn{3}{|c|}{ Adult } \\
\hline$>4$ & $469 / 581$ & 1.0 \\
\hline $0<\mathrm{h} \leq 4$ & $716 / 742$ & $1.17(0.99-1.37)$ \\
\hline 0 & $256 / 211$ & $1.49(1.19-1.86)$ \\
\hline$P_{\text {trend }}$ & 0.0006 & \\
\hline \multicolumn{3}{|l|}{$\operatorname{BMI}\left(\mathrm{kg} / \mathrm{m}^{2}\right)$} \\
\hline$<21$ & $333 / 439$ & 1.0 \\
\hline $21<\mathrm{BMI}<25$ & $679 / 714$ & $1.27(1.06-1.52)$ \\
\hline$>25$ & $443 / 402$ & $1.49(1.21-1.83)$ \\
\hline$P_{\text {trend }}$ & 0.0002 & \\
\hline \multicolumn{3}{|l|}{ Waist/hip ratio } \\
\hline$<0.76$ & $256 / 347$ & 1.0 \\
\hline $0.76<$ waist $/$ hip ratio $<0.84$ & $806 / 868$ & $1.25(1.03-1.51)$ \\
\hline$>0.84$ & $394 / 340$ & $1.60(1.28-2.00)$ \\
\hline$P_{\text {trend }}$ & $<0.0001$ & \\
\hline \multicolumn{3}{|l|}{ Energy intake $(\mathrm{kcal} / \mathrm{d})$} \\
\hline$<1,540$ & $355 / 397$ & 1.0 \\
\hline $1,540<\mathrm{kcal}<2,107$ & $716 / 790$ & $0.99(0.83-1.18)$ \\
\hline$>2,107$ & $388 / 369$ & $1.15(0.93-1.41)$ \\
\hline$P_{\text {trend }}$ & 0.1921 & \\
\hline
\end{tabular}

NOTE: Data were adjusted for age at interview, education, income, history of fibroadenoma, history of breast cancer among first-degree relatives, and ever had live birth. Occupational activity was measured as the average time spent in standing or walking and classified into one of three activity categories (i.e., heavy, medium, or nonphysical work). 
Table 3

Association of adult exercise/sport activity levels, occupational activity levels, BMI, energy intake and breast cancer risk between premenopausal and postmenopausal women (Shanghai Breast Cancer Study, 1996-1999)

\begin{tabular}{|c|c|c|c|c|c|c|}
\hline & \multicolumn{3}{|c|}{ BMI $\left(\mathrm{kg} / \mathrm{m}^{2}\right)$} & \multicolumn{3}{|c|}{ Energy intake (kcal/d) } \\
\hline & Q1 $(<21)$ & $\begin{array}{l}\mathrm{Q} 2-\mathrm{Q3}(21< \\
\mathrm{BMI}<25)\end{array}$ & Q4 (>25) & Q1 $(<1,540)$ & $\begin{array}{c}\text { Q2-Q3 }(1,540 \\
<\mathrm{EI}<2,107)\end{array}$ & Q4 (>2,107) \\
\hline \multicolumn{7}{|c|}{ All women } \\
\hline \multicolumn{7}{|c|}{ Adult exercise/sports (MET-h/d/y) } \\
\hline$>2.92$ & 1.0 & $\begin{array}{c}1.07(0.57- \\
2.00)\end{array}$ & $\begin{array}{c}0.75(0.38- \\
1.47)\end{array}$ & 1.0 & $\begin{array}{c}0.83(0.44- \\
1.56)\end{array}$ & $\begin{array}{c}0.85(0.43- \\
1.69)\end{array}$ \\
\hline $2.92^{0<\mathrm{h} \leq}$ & $\begin{array}{l}1.02(0.51- \\
2.05)\end{array}$ & $\begin{array}{c}1.22(0.66- \\
2.26)\end{array}$ & $\begin{array}{c}1.42(0.74- \\
2.74)\end{array}$ & $\begin{array}{l}1.06(0.53- \\
2.14)\end{array}$ & $\begin{array}{c}1.24(0.67- \\
2.31)\end{array}$ & $\begin{array}{c}1.05(0.54- \\
2.08)\end{array}$ \\
\hline 0 & $\begin{array}{l}1.29(0.74- \\
2.23) \\
0.02\end{array}$ & $\begin{array}{l}1.68(0.98- \\
2.88)\end{array}$ & $\begin{array}{l}2.16(1.25- \\
3.74)\end{array}$ & $\begin{array}{l}1.52(0.87- \\
2.66) \\
0.31\end{array}$ & $\begin{array}{c}1.49(0.86- \\
2.59)\end{array}$ & $\begin{array}{c}1.87(1.06- \\
3.28)\end{array}$ \\
\hline \multirow{2}{*}{\multicolumn{7}{|c|}{$P_{\text {interaction }}$}} \\
\hline & & & & \multicolumn{3}{|c|}{ Occupational activity (h/d/y) } \\
\hline$>4$ & 1.0 & $\begin{array}{c}1.13(0.82- \\
1.56)\end{array}$ & $\begin{array}{c}1.37(0.97- \\
1.94)\end{array}$ & 1.0 & $\begin{array}{c}1.01(0.75- \\
1.38)\end{array}$ & $\begin{array}{c}1.13(0.80- \\
1.59)\end{array}$ \\
\hline $0<\mathrm{h} \leq 4$ & $\begin{array}{l}1.01(0.72- \\
1.41)\end{array}$ & $\begin{array}{c}1.41(1.04- \\
1.92)\end{array}$ & $\begin{array}{c}1.59(1.13- \\
2.23)\end{array}$ & $\begin{array}{l}1.16(0.84- \\
1.62)\end{array}$ & $\begin{array}{c}1.15(0.86- \\
1.54)\end{array}$ & $\begin{array}{c}1.35(0.97- \\
1.88)\end{array}$ \\
\hline 0 & $\begin{array}{l}1.34(0.86- \\
2.09)\end{array}$ & $\begin{array}{l}1.73(1.19- \\
2.54)\end{array}$ & $\begin{array}{c}2.47(1.57- \\
3.88)\end{array}$ & $\begin{array}{l}1.63(1.06- \\
2.50)\end{array}$ & $\begin{array}{l}1.46(1.01- \\
2.11)\end{array}$ & $\begin{array}{l}1.82(1.15- \\
2.88)\end{array}$ \\
\hline & 0.35 & & & 0.95 & & \\
\hline \multicolumn{7}{|l|}{$P_{\text {interaction }}$} \\
\hline \multicolumn{7}{|l|}{ Premenopausal } \\
\hline \multicolumn{7}{|c|}{ Adult exercise/sports (MET-h/d/y) } \\
\hline$>2.92$ & 1.0 & $\begin{array}{c}0.82(0.33- \\
2.03)\end{array}$ & $\begin{array}{c}0.74(0.24- \\
2.30)\end{array}$ & 1.0 & $\begin{array}{c}0.60(0.19- \\
1.88)\end{array}$ & $\begin{array}{c}0.58(0.18- \\
1.89)\end{array}$ \\
\hline $2.92^{0<\mathrm{h} \leq}$ & $\begin{array}{l}0.65(0.26- \\
1.62)\end{array}$ & $\begin{array}{c}0.85(0.36- \\
2.00)\end{array}$ & $\begin{array}{c}0.54(0.20- \\
1.48)\end{array}$ & $\begin{array}{l}0.56(0.18- \\
1.78)\end{array}$ & $\begin{array}{c}0.57(0.19- \\
1.68)\end{array}$ & $\begin{array}{c}0.49(0.15- \\
1.54)\end{array}$ \\
\hline 0 & $\begin{array}{l}0.81(0.38- \\
1.71)\end{array}$ & $\begin{array}{c}1.01(0.48- \\
2.12)\end{array}$ & $\begin{array}{c}1.11(0.52- \\
2.38)\end{array}$ & $\begin{array}{l}0.77(0.28- \\
2.10)\end{array}$ & $\begin{array}{c}0.67(0.25- \\
1.81)\end{array}$ & $\begin{array}{l}0.87(0.32- \\
2.39)\end{array}$ \\
\hline & 0.17 & & & 0.37 & & \\
\hline \multicolumn{7}{|c|}{$P_{\text {interaction }}$} \\
\hline \multicolumn{7}{|c|}{ Occupational activity (h/d/y) } \\
\hline$>4$ & 1.0 & $\begin{array}{c}1.14(0.79- \\
1.65)\end{array}$ & $\begin{array}{c}1.09(0.71- \\
1.68)\end{array}$ & 1.0 & $\begin{array}{c}0.98(0.67- \\
1.44)\end{array}$ & $\begin{array}{c}1.20(0.77- \\
1.87)\end{array}$ \\
\hline $0<\mathrm{h} \leq 4$ & $\begin{array}{l}0.94(0.65- \\
1.38)\end{array}$ & $\begin{array}{c}1.29(0.91- \\
1.83)\end{array}$ & $\begin{array}{c}1.31(0.87- \\
1.98)\end{array}$ & $\begin{array}{l}1.24(0.82- \\
1.86)\end{array}$ & $\begin{array}{c}1.01(0.70- \\
1.46)\end{array}$ & $\begin{array}{c}1.30(0.85- \\
1.97)\end{array}$ \\
\hline 0 & $\begin{array}{l}1.55(0.93- \\
2.58)\end{array}$ & $\begin{array}{l}1.78(1.13- \\
2.80)\end{array}$ & $\begin{array}{l}2.25(1.20- \\
4.20)\end{array}$ & $\begin{array}{l}1.92(1.12- \\
3.29)\end{array}$ & $\begin{array}{l}1.57(0.99- \\
2.51)\end{array}$ & $\begin{array}{c}1.71(0.92- \\
3.19)\end{array}$ \\
\hline & 0.44 & & & 0.37 & & \\
\hline \multicolumn{7}{|l|}{$P_{\text {interaction }}$} \\
\hline \multicolumn{7}{|c|}{ Postmenopausal } \\
\hline \multicolumn{7}{|c|}{ Adult exercise/sports (MET-h/d/y) } \\
\hline$>2.92$ & 1.0 & $\begin{array}{c}1.65(0.65- \\
4.19)\end{array}$ & $\begin{array}{c}1.19(0.45- \\
3.12)\end{array}$ & 1.0 & $\begin{array}{c}0.96(0.43- \\
2.13)\end{array}$ & $\begin{array}{c}0.90(0.37- \\
2.19)\end{array}$ \\
\hline $2.92^{0<\mathrm{h} \leq}$ & $\begin{array}{l}1.68(0.53- \\
5.34)\end{array}$ & $\begin{array}{c}1.80(0.69- \\
4.68)\end{array}$ & $\begin{array}{c}3.30(1.27- \\
8.57)\end{array}$ & $\begin{array}{l}1.32(0.51- \\
3.43)\end{array}$ & $\begin{array}{c}1.85(0.83- \\
4.13)\end{array}$ & $\begin{array}{c}1.55(0.64- \\
3.77)\end{array}$ \\
\hline 0 & $\begin{array}{l}2.07(0.85- \\
5.07) \\
0.12\end{array}$ & $\begin{array}{c}3.00(1.28- \\
7.05)\end{array}$ & $\begin{array}{l}4.74(2.00- \\
11.19)\end{array}$ & $\begin{array}{l}1.82(0.87- \\
3.79)\end{array}$ & $\begin{array}{l}2.51(1.24- \\
5.08)\end{array}$ & $\begin{array}{l}2.71(1.31- \\
5.63)\end{array}$ \\
\hline \multicolumn{7}{|l|}{$P_{\text {interaction }}$} \\
\hline \multicolumn{7}{|c|}{$\begin{array}{l}\text { interaction } \\
\text { Occupational activity }(\mathrm{h} / \mathrm{d} / \mathrm{y})\end{array}$} \\
\hline$>4^{1}$ & 1.0 & $\begin{array}{c}1.14(0.57- \\
2.28)\end{array}$ & $\begin{array}{c}1.94(0.97- \\
3.88)\end{array}$ & 1.0 & $\begin{array}{c}1.11(0.66- \\
1.85)\end{array}$ & $\begin{array}{c}1.01(0.57- \\
1.78)\end{array}$ \\
\hline $0<\mathrm{h} \leq 4$ & $\begin{array}{l}1.26(0.60- \\
2.63)\end{array}$ & $\begin{array}{c}1.81(0.92- \\
3.57)\end{array}$ & $\begin{array}{c}2.17(1.09- \\
4.32)\end{array}$ & $\begin{array}{l}1.01(0.56- \\
1.81)\end{array}$ & $\begin{array}{c}1.51(0.92- \\
2.49)\end{array}$ & $\begin{array}{c}1.45(0.84- \\
2.51)\end{array}$ \\
\hline 0 & $\begin{array}{l}0.97(0.38- \\
2.51) \\
0.64\end{array}$ & $\begin{array}{c}1.83(0.85- \\
3.94)\end{array}$ & $\begin{array}{c}3.13(1.43- \\
6.86)\end{array}$ & $\begin{array}{l}1.25(0.60- \\
2.59) \\
0.34\end{array}$ & $\begin{array}{c}1.36(0.74- \\
2.50)\end{array}$ & $\begin{array}{c}2.06(1.04- \\
4.08)\end{array}$ \\
\hline$P_{\text {interaction }}$ & & & & & & \\
\hline
\end{tabular}

NOTE: Data were adjusted for age at interview, education, income, history of fibroadenoma, history of breast cancer among first-degree relatives, ever had live birth, height, and menopausal status. Occupational activity was measured as the average time spent in standing or walking and classified into one of three activity categories (i.e., heavy, medium, or nonphysical work). 


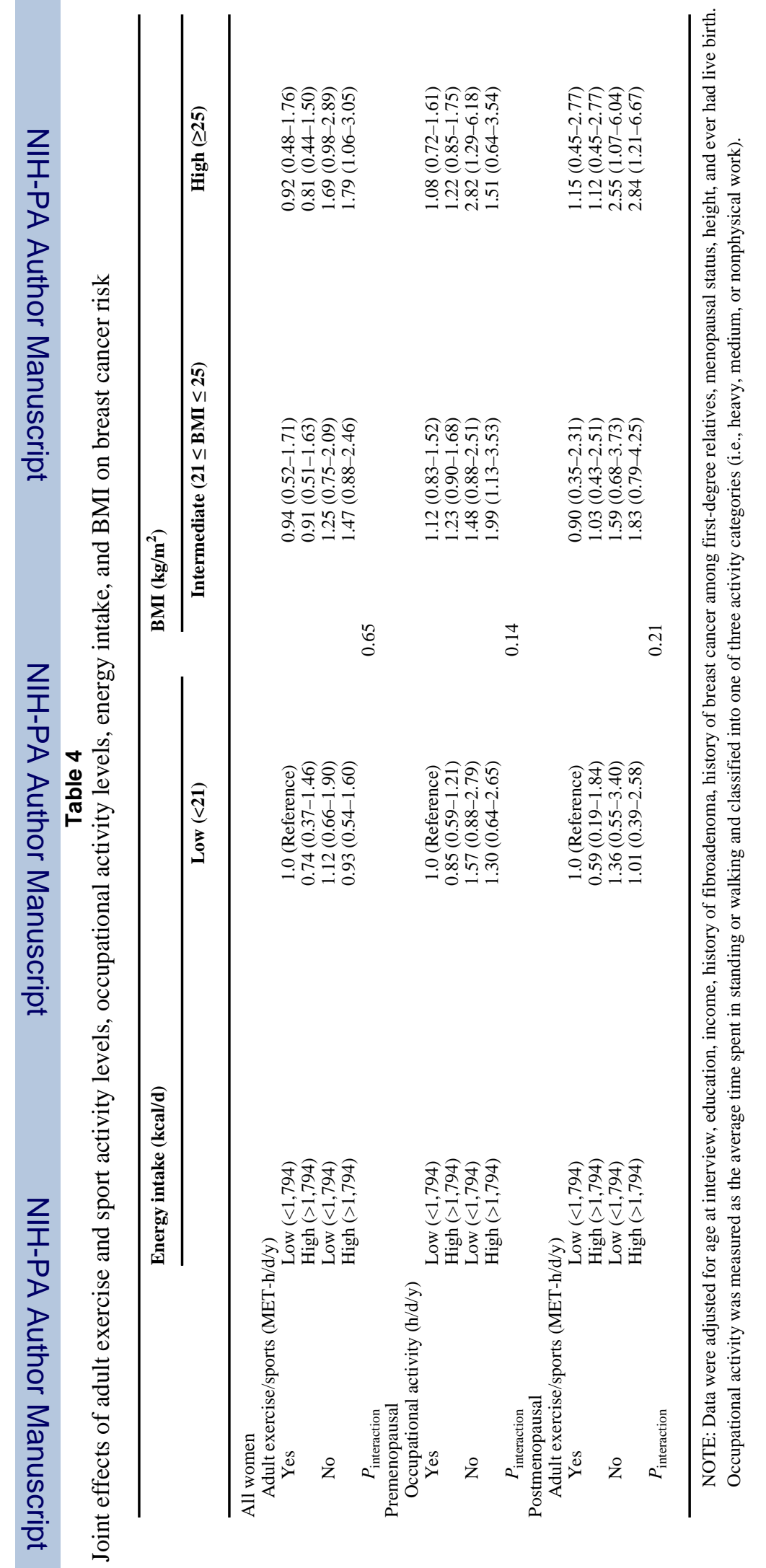

Cancer Epidemiol Biomarkers Prev. Author manuscript; available in PMC 2006 October 10. 